\title{
A Network Analysis of Shariah-Compliant Stocks across Global Financial Crisis: A Case of Malaysia
}

\author{
Fatin Nur Amirah Mahamood ${ }^{1}$, Hafizah Bahaludin $^{1} \&$ Mimi Hafizah Abdullah ${ }^{1}$ \\ ${ }^{1}$ Kulliyyah of Science, International Islamic University Malaysia, Pahang, Malaysia \\ Correspondence: Mimi Hafizah Abdullah, Kulliyyah of Science, International Islamic University Malaysia, \\ Pahang, Malaysia. Tel: 60-123-789-481. E-mail: mimihafizah@iium.edu.my
}

Received: May 3, 2019

Accepted: June 4, 2019

Online Published: June 30, 2019

doi: $10.5539 /$ mas.v13n $7 \mathrm{p} 80$

URL: https://doi.org/10.5539/mas.v13n7p80

The research is financed by Ministry of Higher Education (FRGS 15-191-0432) and International Islamic University Malaysia (P-RIGS18-031-0031).

\begin{abstract}
Financial network is a complex system in which transaction of securities take place. Due to its complexity, a minimum spanning tree (MST) technique is used to visualize the structure. This paper investigates the topological structure of 125 shariah-compliant stocks traded in Bursa Malaysia from the year 2000 until 2017. Financial networks of the shariah-compliant stocks are constructed using MST for three duration periods namely the precrisis, during crisis and post-crisis. To determine the important stocks in the networks, centrality measures are applied such as degree centrality, betweenness centrality, closeness centrality and eigenvector centrality. Lastly, overall centrality measures are computed to identify the overall characteristic of each node. The findings showed that, KUB Malaysia Berhad was the most influential stock in the pre-crisis and crisis periods. While, MK Land Holdings was the main stock in the post-crisis network.
\end{abstract}

Keywords: financial network, minimum spanning tree (MST), centrality measures, shariah-compliant stocks

\section{Introduction}

A network can be defined as a set of items, called vertices or nodes and connections between the nodes as links or edges. There are various types of networks such as the Internet, the World Wide Web, social networks, business networks, food webs, distribution networks, technological networks, biological networks and financial market network is one of them. Briefly, a financial market is a trading floor where transaction of securities consists of equities, bonds, currencies, and derivatives take place. Therefore, a financial market network consists of nodes which represent the stocks and the links represent the correlation between stocks. Basically, the correlation between stocks is based on a stock's price. The fluctuation of a stock's price from time to time exhibits a very complicated and complex system since the changes occur in the stock prices will affect other stock prices too. This complexity consequently makes the financial network a fascinating network which attracted much attention from many researchers to further investigate its structures and characterizations. In addition, the complex correlation elements make the financial network difficult to visualize.

Minimum spanning tree (MST) method is a common approach to visualize and simplify stocks correlation network. MST can be defined as a spanning tree with minimum weights. The application of MST is not only in finance, but is also widely used in other fields such as in industry (Sharif \& Djauhari, 2012b), transportations (Asrah, Djauhari, $\&$ Mohamad, 2017) and politics (Laud, 2015). Furthermore, in finance, MST method has been a very popular method to analyze stocks' correlations since it was introduced by Mantegna (1999). Instead of $N \times N$ correlation elements, it can be reduced to only $N(N-1) / 2$ correlation elements and produce $N-1$ links where $N$ is the number of stocks. Since decades ago, numerous studies have applied this method to analyze the financial market, for example, Bonanno et al., (2004), Zhuang, Hu and Ye (2008), Jang, Lee and Chang (2011), Djauhari (2012), Cheong et al., (2012), Djauhari and Gan (2013, 2015), Majapa and Gossel (2016) and Coletti (2016). In Malaysian market, Sharif and Djauhari (2012a), Djauhari and Gan (2014), Bahaludin et al., (2015), Yee and Salleh (2018) and Yee et al., (2018) are among the studies investigated a financial network by using MST technique.

All those studies revealed that, there are dominant nodes and also sectors in the network that influence the 
topological structures. For instance, in Malaysian market, Gan and Djauhari (2012), Bahaludin et al., (2015), Yee and Salleh (2018) and Yee et al., (2018) studied the top 100 companies based on market capitalization with different time ranges. In the year 2007 until 2009, Gan and Djauhari (2012) found two main clusters with EUMS and BURSA as the key stocks. Later, Bahaludin et al., (2015) obtained three dominant stocks from the year 2011 until 2013, in which two of them are the same stocks found in Gan and Djauhari (2012) and the third stock was UEMS. Recently, Yee and Salleh (2018) continued the study of Bursa Malaysia market performance over the period of 2011 to 2017. They determined four main groups in the network dominated by MALAYAN, AFFIN, MRCB and CIMB.

Moreover, all the authors above used conventional stocks in their studies. Until now, there is no study that analyzes financial market network for shariah-compliant stocks by using MST. Thus, in this perspective, this study aims to investigate the topological structure of shariah-compliant stocks traded in Bursa Malaysia from $28^{\text {th }}$ March 2000 until $29^{\text {th }}$ December 2017 by using MST method. For this purpose, the duration of the study is divided into precrisis, crisis and post-crisis periods. In this study, the aim is to determine the most influential shariah-compliant stocks in terms of degree centrality, betweenness centrality, closeness centrality and eigenvector centrality for each period. Lastly, the overall role of the stocks is measured by using the Principal Component Analysis (PCA).

This paper is organized as follows. In the next section, this paper presents the data and methodology followed by a discussion on the findings and analysis in section 3. Finally, in section 4 conclusion was made from the results obtained.

\section{Data and Methodology}

Data are collected from Eikon Datastream based on the stocks listed in Bursa Malaysia and the Shariah Advisory Council (SAC) from $28^{\text {th }}$ March 2000 until $29^{\text {th }}$ December 2017. Analysis is divided into three periods namely precrisis (2000-2006), crisis (2007-2009) and post-crisis (2010-2017). The crisis period is similar to the work of Asmild, Kronborg, Tasmina and Kent (2018). Across all the periods, there are 4,471 daily closing prices for one hundred and twenty-five (125) consistently listed as shariah-compliant companies from the year 2000 until 2017. The list of 125 shariah-compliant companies and their corresponding codes is presented in the Appendix. The next subsection explains shariah-compliant stock, followed by the procedures of the MST and centrality measures.

\subsection{Shariah-Compliant Stocks}

Securities Commission Malaysia (SC) is a legal organization entrusted with the responsibilities of regulating and systematically developing Malaysia's capital markets by providing a list of securities that has been examined as shariah compliance. In determining the Shariah-compliant status of the listed securities, Securities Commission Malaysia (2018) set up some criteria which need to be fulfilled by companies. The criteria are, the company must be free from interest (riba), gambling (maysir), doubtful transactions or uncertainty (gharar), and forbidden (haram) activities, for example, involvement in alcohol and pig farming. The shariah principles concentrated on the core business activities of the companies. It is worth to note that, if a company comprises halal and non-halal activities, it is shariah-compliant if and only if the non-halal activities are very small compared to the core activities, as well as its images and public perceptions are good. Furthermore, the core activities contribute to the people and the country.

\subsection{Minimum Spanning Tree (MST)}

MST is a well-known method to simplify the complexity of the correlation networks. There are four simple steps to create MST network. Firstly, logarithmic returns of daily closing prices are calculated and a correlation matrix is computed by using Pearson's correlation coefficient (PCC). Next, the correlation coefficient is transformed into a distance matrix as conducted by Mantegna (1999) and Mantegna and Stanley (2000). In the consequential MST, each node represents a shariah-compliant stock in Bursa Malaysia and their distances are analyzed and taken as their strengths in terms of their correlations between stocks $i$ and $j$.

The procedures to construct a network using MST are as follows. If $P_{i}(t)$ is denoted as the closing stock price of a company $i(i=1 \ldots N)$ at time $t$, then logarithmic return is calculated as:

$$
r_{i}(t)=\ln P_{i}(t)+\ln P_{i}(t)
$$

Let $C$ be a correlation of $N \times N$ matrix, where $N$ is the number of stocks. While, $\rho_{i j}$, is a correlation coefficient between stocks $i$ and $j$ calculated by using a Pearson's Correlation Coefficient formula: 


$$
\rho_{i j}=\frac{\left\langle r_{i} r_{j}\right\rangle-\left\langle r_{i}\right\rangle\left\langle r_{j}\right\rangle}{\sqrt{\left(\left\langle r_{i}^{2}\right\rangle-\left\langle r_{i}\right\rangle^{2}\right)\left(\left\langle r_{j}^{2}\right\rangle-\left\langle r_{j}\right\rangle^{2}\right)}}
$$

Then, a correlation coefficient, $\rho_{i j}$, is transformed into a distance matrix, denoted by:

$$
d_{i j}=\sqrt{2\left(1-\rho_{i j}\right)}
$$

Lastly, the MST is constructed by using a Kruskal's algorithm as Kruskal's algorithm is one of the standard practice to find MST (Graham \& Hell, 1985; Keskin, Deviren, \& Kocakaplan, 2011; Mantegna, 1999; Mantegna \& Stanley, 2000). The advantages of using the Kruskal's algorithm are that it is mathematically appealing (Malkevitch, 2012), easy to formulate although it is not the fastest algorithm (Nesetril, 1997) and no optimality problem occurs since the result of Kruskal's algorithm is independent of node ordering (Djauhari \& Gan, 2013, 2014).

\subsection{Centrality Measures}

A centrality measure reveals the most influential stocks in the network. There are four commonly used centrality measures in many studies such as degree centrality, betweenness centrality, closeness centrality and eigenvector centrality (Coletti, 2016; Coletti \& Murgia, 2016; Yee \& Salleh, 2018; Yee et al., 2018). In addition, an overall centrality measure is calculated to determine an overall role of each stock.

To begin with, degree centrality, $C_{D}(i)$, is to identify the most important node (stock) with respect to the number of linked nodes (Freeman, 1978). It is calculated using the following formula:

$$
C_{D}(i)=\frac{\sum_{j}^{N} A_{i j}}{N-1}
$$

where $A_{i j}=1$ if the stock $i$ and stock $j$ are linked and 0 otherwise. According to Freeman (1977), betweenness centrality, $C_{B}(i)$ shows the ability of a particular node to control others by controlling the information flows between them. It is computed as follows:

$$
C_{B}(i)=\sum_{j<k} \frac{g_{j k}(i)}{g_{j k}}
$$

where, $g_{j k}(i)$ is the number of shortest paths from stock $j$ to stock $k$ that pass-through stock $i$. Meanwhile, $g_{j k}$ is the total number of shortest paths from $j$ to $k$, where $j \neq i$ and $k \neq i$. The value of closeness centrality, $C_{C}(i)$ reveals the nearest distance between stock $i$ and stock $j$, relatively. The closeness centrality of stock $i, C_{C}(i)$ is mathematically defined as:

$$
C_{C}(i)=\left[\sum_{j=1}^{N} d(i, j)\right]^{-1}
$$

where $d(i, j)$ is the shortest path from stock $i$ to stock $j$. Lastly, the concept of eigenvector centrality is to determine a node's importance in a network by asserting links to another node that are themselves influential (Bonacich, 1987). Eigenvector centrality is denoted as:

$$
e(i)=\lambda^{-1} \sum_{j=1}^{N} A_{i j} x_{j} \text { for } i=1,2, \ldots N .
$$

Additionally, the expression is also can be written as

$$
A_{i j} e(i)=\lambda e(i)
$$

where $A_{i j}$ is an adjacency matrix and $e(i)$ is an eigenvector of a largest eigenvalue, $\lambda$.

\subsection{Overall Centrality Measures}

In order to identify the overall role of each stock, an overall centrality measure is calculated by using principal component analysis (PCA), similar to the seminal work of Lee and Djauhari (2012), Pasini (2017) and Yee and Salleh (2018). 
The investigation of an overall role of each stock produces a very large and complex data set since a matrix of $N$ $\times 4$ is computed where $N$ is the number of stocks and 4 is denoted as the four centrality measures of stock $i$. In order to reduce this complexity and minimizes the information loss, PCA method is applied (Jolliffe, 2002). In general, the correlated variables are transformed into a new set of uncorrelated variables which is called as principal components (PCs). The PCs are arranged in a sequence in which the PC with the largest eigenvalue is considered. Then, its eigenvector is computed in which each element of the eigenvectors is a linear combination of the original variables.

Firstly, matrix of $N \times 4$ and a covariance matrix of $S$ are computed. Secondly, eigenvector, $\mathbf{v}=\left(v_{1}, v_{2}, v_{3}, v_{4}\right)$ associated with the largest eigenvalue, $\theta_{\max }$ is calculated by using the formula $S \mathbf{v}=\theta_{\max } \mathbf{v}$. Then, the overall centrality measure score of stock $i$ is determined by

$$
O(i)=v_{1} C_{D}(i)+v_{2} C_{B}(i)+v_{3} C_{C}(i)+v_{4} e(i)
$$

\section{Results and Discussions}

In this section, the examining of the MST of shariah-compliant companies in Malaysian market for the three durations which are pre-crisis (2000-2006), during crisis (2007-2009) and post-crisis (2010-2017). The data collected consists of 125 stocks which are consistently classified in eight economic sectors based on SAC's list traded since the year 2000 until 2017. However, during crisis period, only 124 companies are used since Teo Guan Lee Construction (9396) from the consumer sector is removed due to the unavailability of data.

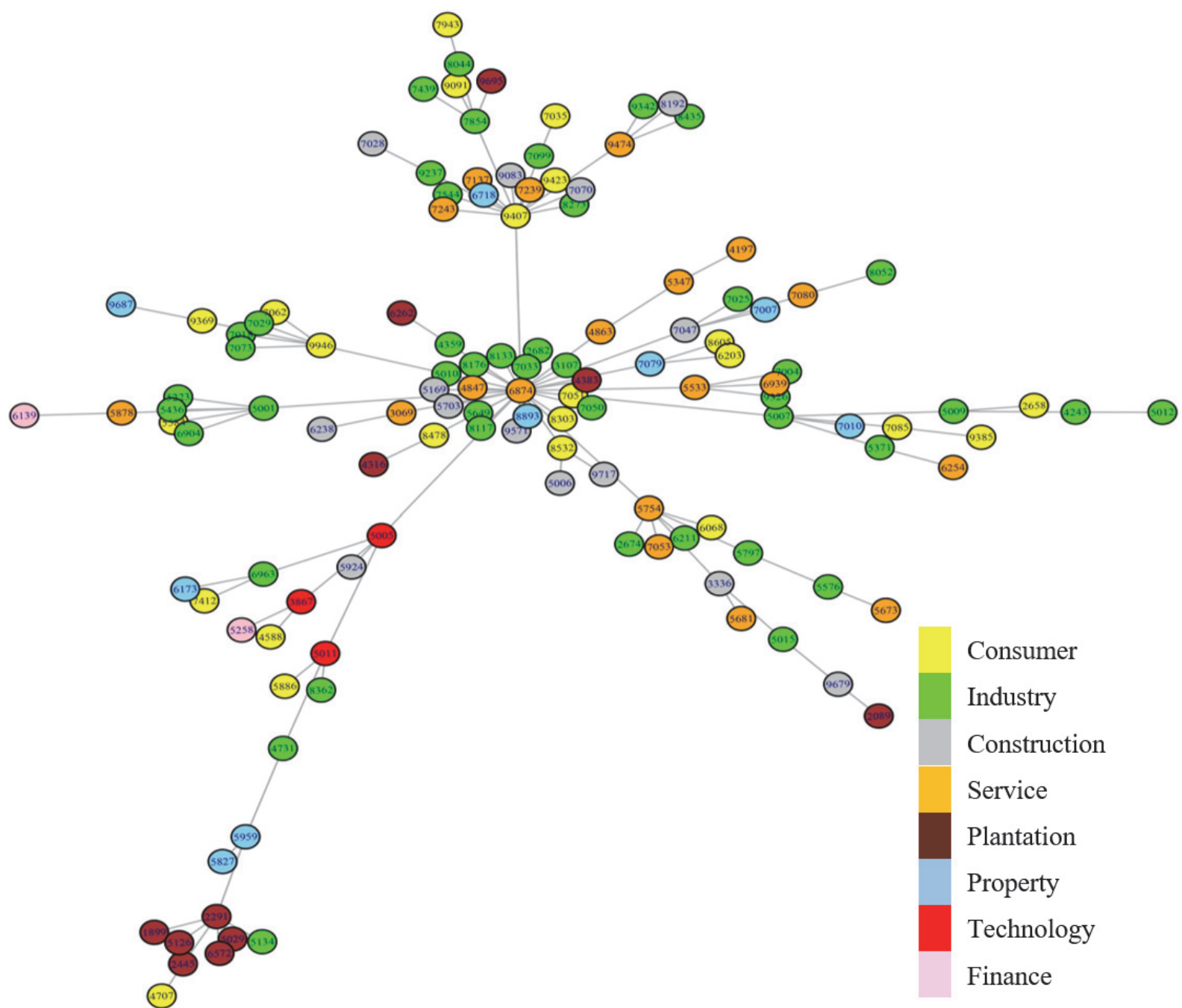

Figure 1. Minimum Spanning Tree (MST) of a pre-crisis period from the year 2000 until 2006 


\subsection{Minimum Spanning Tree (MST)}

Figure 1 until Figure 3 present the evolution of MST from the three periods (pre-crisis, during crisis and postcrisis). Figure 1 portrays that, there were seven main clusters during the pre-crisis period and was dominated by KUB Malaysia Berhad (6874) with 31 stocks connected to it. Next is Paragon Union (9407) with a number of links of 14, Utusan Melayu Malaysia (5754) and Genting Plantation (2291) shared the same number of links which is 7, while Rex Industry (9946) and Mieco Chipboard (5001) have the same number of links which is 6. Lastly, Unisem (5005) has 5 stocks linked to it.

Figure 2 presents three main groups in the crisis period network in which KUB Malaysia Berhad (6874) was the key node with 28 stocks linked to it. Then, with 13 links, Batu Kawan (1899) was the second group. The third goup was Muhibbah Engineering (5703) having 8 stocks connected to it. The crisis period network shows that the stocks had low connections with other stocks compared to the pre-crisis period.

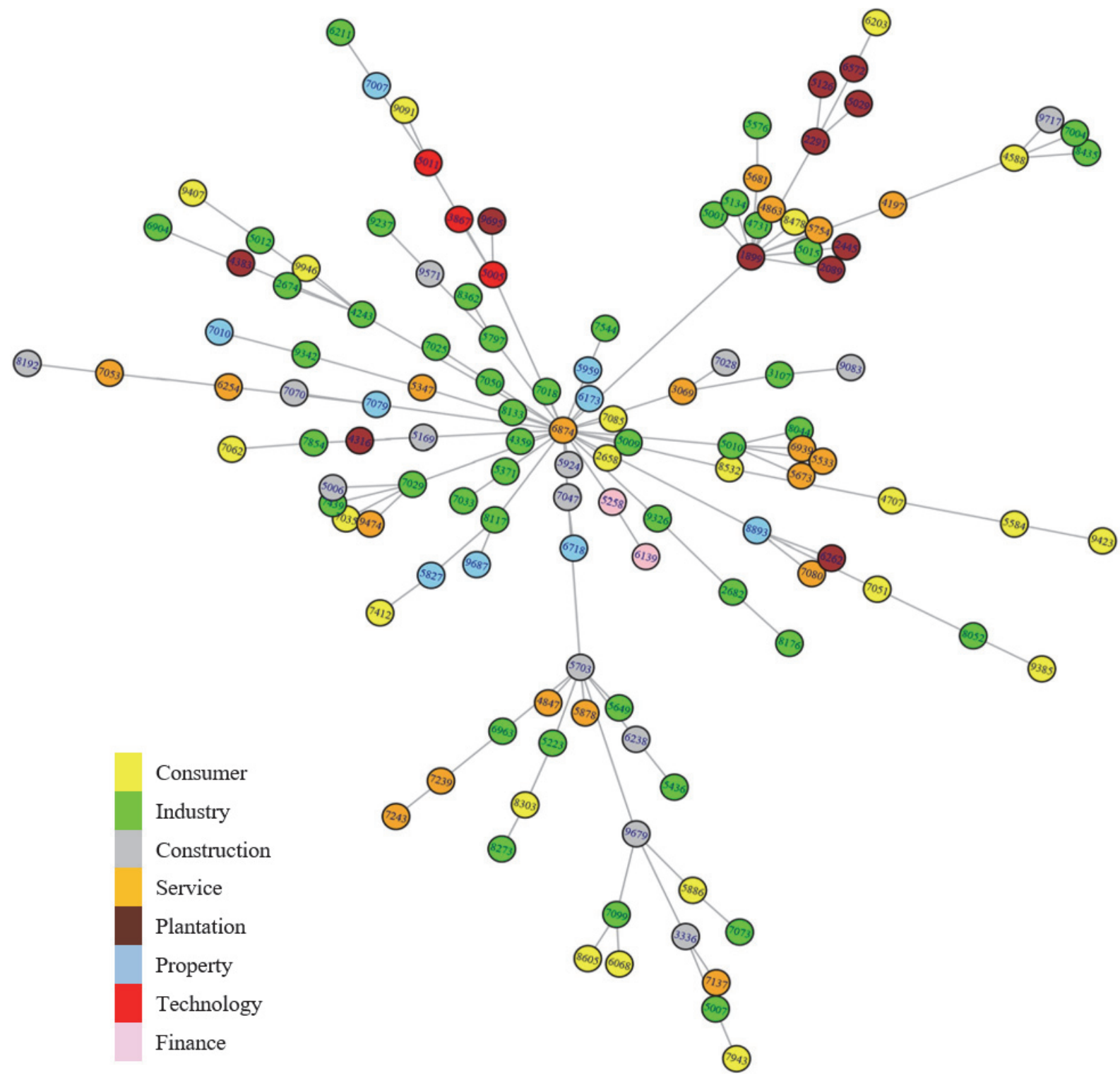

Figure 2. Minimum Spanning Tree (MST) of a crisis period from the year 2007 until 2009

After the turmoil period, Figure 3 portrayed five main clusters in the network with MK Land Holdings (8893) as the most influential stocks with a number of links of 23, tailed by Muhibbah Engineering (5703) with 18 stocks linked to it. The third and fourth clusters were dominated by WTK Holdings (4243) and KUB Malaysia Berhad (6874) respectively, with 12 stocks connected to each of them. Lastly, VS Industry (6963) has 4 number of links. 


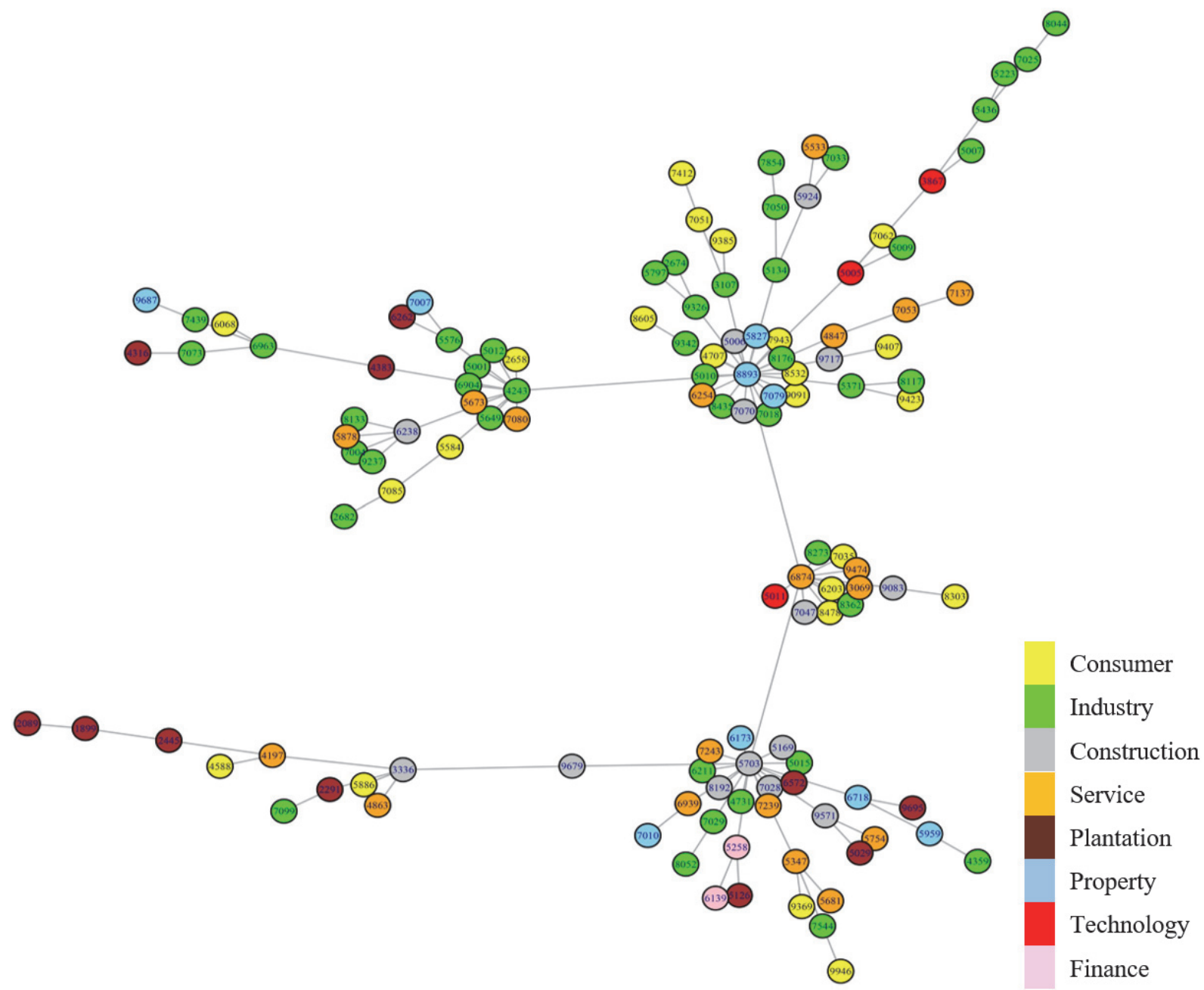

Figure 3. Minimum Spanning Tree (MST) of a post-crisis period from the year 2010 until 2017

\subsubsection{Degree Centrality}

Degree centrality is the number of links connected directly to a node (Freeman, 1978). Normally, node with higher number of links connected to it, is the most important node in terms of degree centrality. Table 1 until Table 3 reveal the top five nodes which have the highest degree centrality for each duration. Table 1 until Table 3 show that KUB Malaysia Berhad (6874) has the highest degree values in pre-crisis and crisis periods which are 0.250 in pre-crisis and decrease during crisis with a degree value of 0.228 as depicted in Table 1 and Table 2. Unfortunately, after the crisis period, KUB Malaysia Berhad decreases to the third rank with 0.097 degree value. While, MK Land Holdings (8893) has the highest rank with a degree value of 0.185 as shown in Table 3. Besides, as observed in Table 1 and Table 2, there are no consistent stocks listed as top five in the degree centrality scores in pre-crisis and crisis periods except for KUB Malaysia Berhad (6874). This signifies that, there was a restructuring of the network in order to acclimatize during a tremendous period.

Table 2 and Table 3 further reveal that, only three stocks are consistently appear as having the uppermost score in crisis and post-crisis periods. The stocks are Muhibbah Engineering (5703), WTK Holdings (4243) and KUB Malaysia Berhad (6874). It explains that, there was a recovery in stocks which is Muhibbah Engineering (5703), which has increase in its degree value from 0.065 in the crisis period to 0.145 in post-crisis period. In addition, WTK Holdings (4243) shows an arising value from 0.041 during crisis period to 0.097 in post-crisis period. Nevertheless, the value for KUB Malaysia Berhad (6874), has sharply decrease from 0.228 to 0.097 . Moreover, Table 3 tells that, there were stocks in the post-crisis period that entered the top five list after the crisis period. Example of the stocks are MK Land Holdings (8893), Hock Seng Lee (6238), IJM Corporation (3336) and VS Industry (6963). In other words, these stocks increase in the number of incident links after the crisis period.

Further, in Table 1 and Table 2 expose that the service sector was the strongest sector before crisis and during crisis 
periods. Then, it was replaced by the property sector in the post-crisis period as illustrated in Table 3 . Table 2 also displays that the industry sector played an important role since there are three out of five stocks belongs to the industry sector. Similar to the construction sector, it was also an influential sector during the post-crisis period as it appears three times in Table 3. Thus, this shows that, these sectors have many stocks linked to them which make them the most crucial stocks across all periods.

Table 1. The highest degree centrality values for the pre-crisis period (2000-2006)

\begin{tabular}{lllll}
\hline No & Name & Code & Sector & Degree \\
\hline 1 & KUB Malaysia Berhad & 6874 & Service & 0.250 \\
2 & Paragon Union & 9407 & Consumer & 0.113 \\
3 & Utusan Melayu Malaysia & 5754 & Service & 0.056 \\
4 & Genting Plantations & 2291 & Plantation & 0.056 \\
5 & Rex Industry & 9946 & Consumer & 0.048 \\
6 & Mieco Chipboard & 5001 & Industry & 0.048 \\
7 & Chin Well Holdings & 5007 & Industry & 0.040 \\
\hline
\end{tabular}

Table 2. The highest degree centrality values for the crisis period (2007-2009)

\begin{tabular}{lllll}
\hline No & Name & Code & Sector & Degree \\
\hline 1 & KUB Malaysia Berhad & 6874 & Service & 0.228 \\
2 & Batu Kawan & 1899 & Plantation & 0.106 \\
3 & Muhibbah Engineering & 5703 & Construction & 0.065 \\
4 & Master-Pack Group & 7029 & Industry & 0.041 \\
5 & Tong Herr Resources & 5010 & Industry & 0.041 \\
6 & WTK Holdings & 4243 & Industry & 0.041 \\
7 & UMW Holdings & 4588 & Consumer & 0.033 \\
\hline
\end{tabular}

Table 3. The highest degree centrality values for the post-crisis period (2010-2017)

\begin{tabular}{lllll}
\hline No & Name & Code & Sector & Degree \\
\hline 1 & MK Land Holdings & 8893 & Property & 0.185 \\
2 & Muhibbah Engineering & 5703 & Construction & 0.145 \\
3 & WTK Holdings & 4243 & Industry & 0.097 \\
4 & KUB Malaysia Berhad & 6874 & Service & 0.097 \\
5 & Hock Seng Lee & 6238 & Construction & 0.040 \\
6 & IJM Corporation & 3336 & Construction & 0.040 \\
7 & VS Industry & 6963 & Industry & 0.032 \\
\hline
\end{tabular}

\subsubsection{Betweenness Centrality}

Freeman (1978) stated that, betweenness centrality is a method to determine the importance of a node as an intermediary. The node that has the highest betweenness centrality value is interpreted as having the ability to control the information flow within a network. Thus, the node is considered as the most influential node in terms of betweenness centrality measure. The findings expose that the top five of betweenness centrality measure for three periods are presented in Table 4 until Table 5.

Across pre-crisis and crisis periods, KUB Malaysia Berhad (6874) remained as the highest rank with betweenness centrality values of 0.908 in pre-crisis period and 0.921 in crisis period as described in Table 4 and Table 5 . Therefore, the information must pass through KUB Malaysia Berhad before it reached other stocks. In other words, KUB Malaysia Berhad controlled the information flow in the networks. Thus, KUB Malaysia Berhad was the most influential stock in both pre-crisis and crisis periods networks. Additionally, the highest value of betweenness centrality of KUB Malaysia Berhad indicates that the service sector was the most important sector in Malaysian Islamic market during those periods. However, the betweenness value of KUB Malaysia Berhad (6874) decreased slightly after crisis period with a score of 0.557 as portrayed in Table 6 . In the recovery phase, Table 5 painted MK Land Holdings (8893) as having the highest score in betweenness centrality value of 0.767 . The post-crisis period displays an increased intermediary influence of Muhibbah Engineering (5703) and WTK Holding (4243). 
Muhibbah's betweenness value has increased in value from 0.306 during crisis period to 0.532 in post-crisis period, while WTK's value has sharply increased from 0.095 to 0.359 as shown in Table 6 .

The findings in Table 4 and Table 5 show that there are no consistent stocks listed as the top five in pre-crisis and crisis periods except for KUB Malaysia Berhad (6874). In contrast, there are four stocks consistently appear in the top five list in the crisis and post-crisis periods which are KUB Malaysia Berhad (6874), Muhibbah Engineering Berhad (5703), WTK Holdings (4243) and WCT Holdings (9679). Above all, only KUB Malaysia Berhad (6874) appears across all periods of study. Thus, it concludes that, KUB Malaysia Berhad (6874) was a good mediator in all periods. Likewise, it makes the service sector as an important sector. Besides, property sector also played an influential sector in the post-crisis period.

Table 4. The highest betweenness centrality values for the pre-crisis period (2000-2006)

\begin{tabular}{lllll}
\hline No & Name & Code & Sector & Betweenness \\
\hline 1 & KUB Malaysia Berhad & 6874 & Service & 0.908 \\
2 & Paragon Union & 9407 & Consumer & 0.334 \\
3 & Unisem & 5005 & Technology & 0.298 \\
4 & Mesiniaga & 5011 & Technology & 0.192 \\
5 & Utusan Melayu Malaysia & 5754 & Service & 0.183 \\
\hline
\end{tabular}

Table 5. The highest betweenness centrality values for the crisis period (2007-2009)

\begin{tabular}{lllll}
\hline No & Name & Code & Sector & Betweenness \\
\hline 1 & KUB Malaysia Berhad & 6874 & Service & 0.921 \\
2 & Batu Kawan & 1899 & Plantation & 0.310 \\
3 & Muhibbah Engineering & 5703 & Construction & 0.306 \\
4 & WCT Holdings & 9679 & Construction & 0.140 \\
5 & WTK Holdings & 4243 & Industry & 0.095 \\
\hline
\end{tabular}

Table 6. The highest betweenness centrality values for the post-crisis period (2010-2017)

\begin{tabular}{lllll}
\hline No & Name & Code & Sector & Betweenness \\
\hline 1 & MK Land Holdings & 8893 & Property & 0.767 \\
2 & KUB Malaysia Berhad & 6874 & Service & 0.557 \\
3 & Muhibbah Engineering & 5703 & Construction & 0.532 \\
4 & WTK Holdings & 4243 & Industry & 0.359 \\
5 & WCT Holdings & 9679 & Construction & 0.149 \\
\hline
\end{tabular}

\subsubsection{Closeness Centrality}

Closeness centrality is defined as a measure of the average shortest distance from one stock to all the other stocks (Freeman, 1978). Besides, closeness centrality quantifies how quick the information is distributed to all other stocks in the network. The top five of closeness centrality measures is depicted in Table 7 until Table 9.

Analysis reveals that KUB Malaysia Berhad (6874) continues to be the top scorer in closeness centrality for both periods, pre-crisis and crisis with a score of 0.357 in pre-crisis and increase a little bit during the turmoil period with a score of 0.381 as displayed in Table 7 and Table 8. In the next period, in Table 9, KUB Malaysia Berhad (6874) was replaced by MK Land Holdings (8893) with a score of 0.292. Remarkably, MK Land Holdings (8893) jumped from the fourth place in the crisis period to first place during post-crisis period. Besides, KUB Malaysia Berhad (6874) and Unisem (5005) remained in the top five list for all periods. This result discloses that all other stocks were closely connected to KUB Malaysia Berhad (6874) and Unisem (5005) across all periods.

This investigation also reveals that the property sector was the most influential sector in the post-crisis period, while, the service sector was the most influential sector in both before and during crises. In general, KUB Malaysia Berhad (6874) and MK Land Holdings (8893) were near to other stocks in the networks. Also, it can be said that, the crisis spread through these key stocks. 
Table 7. The highest closeness centrality scores for the pre-crisis period (2000-2006)

\begin{tabular}{lllll}
\hline No & Name & Code & Sector & Closeness \\
\hline 1 & KUB Malaysia Berhad & 6874 & Service & 0.357 \\
2 & Paragon Union & 9407 & Consumer & 0.284 \\
3 & Unisem & 5005 & Technology & 0.283 \\
4 & Utusan Melayu & 5754 & Service & 0.272 \\
5 & Chin Well Holdings & 5007 & Industry & 0.264 \\
\hline
\end{tabular}

Table 8 . The highest closeness centrality scores for the crisis period (2007-2009)

\begin{tabular}{lllll}
\hline No & Name & Code & Sector & Closeness \\
\hline 1 & KUB Malaysia Berhad & 6874 & Service & 0.381 \\
2 & Muhibbah Engineering & 5703 & Construction & 0.306 \\
3 & Batu Kawan & 1899 & Plantation & 0.300 \\
4 & MK Land Holdings & 8893 & Property & 0.290 \\
5 & Unisem & 5005 & Technology & 0.279 \\
\hline
\end{tabular}

Table 9. The highest closeness centrality scores for the post-crisis period (2010-2017)

\begin{tabular}{lllll}
\hline No & Name & Code & Sector & Closeness \\
\hline 1 & MK Land Holdings & 8893 & Property & 0.292 \\
2 & KUB Malaysia Berhad & 6874 & Service & 0.278 \\
3 & Muhibbah Engineering & 5703 & Construction & 0.250 \\
4 & WTK Holdings & 4243 & Industry & 0.242 \\
5 & Unisem & 5005 & Technology & 0.223 \\
\hline
\end{tabular}

\subsubsection{Eigenvector Centrality}

According to Newman (2010) eigenvector centrality is a natural extension of the simple degree centrality. This measure shows the neighbour of a particular node, and also plays crucial roles in determining the importance of a node. It also can be said that, the stock (node) with the highest eigenvector centrality measure indicates that it is connected to the stock with a high degree scoring. Table 10 until Table 12 illustrate the top five highest eigenvector centrality measures in all periods.

Table 10 and Table 11 portray that KUB Malaysia Berhad (6874) has the highest scoring in both pre-crisis and crisis periods with scores of 0.679 and 0.674 , respectively. Unfortunately, with a value of 0.23 , it made KUB Malaysia Berhad (6874) as the second important stock during post-crisis as revealed by Table 12. MK Land Holdings (8893) replaced KUB Malaysia Berhad (6874) as the uppermost score during post-crisis period with a score of 0.654 . Thus, MK Land Holdings dominated the network in terms of eigenvector centrality during postcrisis period. Interestingly, the results show that there are no consistent stocks listed in the top five except for KUB Malaysia Berhad across all durations of the study.

Generally, the service sector with KUB Malaysia Berhad took over the network in both before crisis and during crisis periods. While, property sector was the strongest sector in post-crisis period with MK Land Holdings as the important stock. In other words, these stocks had many important stocks connected to them.

Table 10. The highest eigenvector centrality scores for the pre-crisis period (2000-2006)

\begin{tabular}{lllll}
\hline No & Name & Code & Sector & Eigenvector \\
\hline 1 & KUB Malaysia Berhad & 6874 & Service & 0.679 \\
2 & Paragon Union & 9407 & Consumer & 0.202 \\
3 & Rex Industry & 9946 & Consumer & 0.136 \\
4 & Utusan Melayu Malaysia & 5754 & Service & 0.136 \\
5 & Mieco Chipboard & 5001 & Industry & 0.134 \\
\hline
\end{tabular}


Table 11. The highest eigenvector centrality scores for the crisis period (2007-2009)

\begin{tabular}{lllll}
\hline No & Name & Code & Sector & Eigenvector \\
\hline 1 & KUB Malaysia Berhad & 6874 & Service & 0.674 \\
2 & Batu Kawan & 1899 & Plantation & 0.191 \\
3 & Master-Pack Group & 7029 & Industry & 0.160 \\
4 & Tong Herr Resources & 5010 & Industry & 0.146 \\
5 & Ho Hup Construction & 5169 & Construction & 0.141 \\
\hline
\end{tabular}

Table 12. The highest eigenvector centrality scores for the post-crisis period (2010-2017)

\begin{tabular}{lllll}
\hline No & Name & Code & Sector & Eigenvector \\
\hline 1 & MK Land Holdings & 8893 & Property & 0.654 \\
2 & KUB Malaysia Berhad & 6874 & Service & 0.233 \\
3 & WTK Holdings & 4243 & Industry & 0.211 \\
4 & Southern Acids (M) & 5134 & Industry & 0.145 \\
5 & Fima Corporation & 3107 & Industry & 0.141 \\
\hline
\end{tabular}

\subsection{Overall Centrality Measure}

From the above centrality measures, each of the measures has a unique definition. It defines that each of the centrality measures has distinctive characteristics. So, to determine the most prominent stocks with overall characteristics, an overall centrality measure is computed by using Principal Component Analysis (PCA), similar to the seminal work of Lee and Djauhari (2012), Pasini (2017) and Yee and Salleh, (2018). Tables 13 until Table 15 show the proportion of variance for the first principal component pre-crisis period which is $83.19 \%, 85.78 \%$ is in the crisis period and $83.49 \%$ in the post-crisis period. It is effectively acceptable to identify the overall centrality measure as mentioned by Jolliffe (2002). Consequently, the overall centrality measure is computed and the five most influential stocks are exhibited in Table 13 until Table 15.

KUB Malaysia Berhad (6874) played a very crucial role in the networks of pre-crisis and crisis periods as displayed in Table 13 and Table 14 with scores of 1.112 and 1.115, respectively. While, in Table 12, the post-crisis period, MK Land Holdings (8893) with a score of 0.968 has replaced KUB Malaysia Berhad (6874) as the highest scoring in the overall centrality measure. This analysis tells us that, KUB Malaysia Berhad (6874) and MK Land Holdings (8893) have repeatedly appeared as the highest scoring in all centrality measures and all durations of study. As can be observed from Table 13 until Table 15, even though Unisem (5005) was not having the highest score in the overall centrality measure, but it consistently was in the list in all periods of study. This makes Unisem (5005) also one of the influential stocks.

Hence, the results from the overall centrality measure expose that the service sector, property sector and technology sector were crucial sectors in the networks across all periods.

Table 13. The highest overall centrality scores for the pre-crisis period (2000-2006)

\begin{tabular}{lllll}
\hline No & Name & Code & Sector & Overall Score \\
\hline 1 & KUB Malaysia Berhad & 6874 & Service & 1.112 \\
2 & Paragon Union & 9407 & Consumer & 0.360 \\
3 & Unisem & 5005 & Technology & 0.272 \\
4 & Utusan Melayu Malaysia & 5754 & Service & 0.193 \\
5 & Chin Well Holdings & 5007 & Industry & 0.152 \\
\hline
\end{tabular}

Table 14. The highest overall centrality scores for the crisis period (2007-2009)

\begin{tabular}{lllll}
\hline No & Name & Code & Sector & Overall Score \\
\hline 1 & KUB Malaysia Berhad & 6874 & Service & 1.115 \\
2 & Batu Kawan & 1899 & Plantation & 0.334 \\
3 & Muhibbah Engineering & 5703 & Construction & 0.292 \\
4 & WTK Holdings & 4243 & Industry & 0.124 \\
5 & Unisem & 5005 & Technology & 0.117 \\
\hline
\end{tabular}


Table 15. The highest overall centrality scores for the post-crisis period (2010-2017)

\begin{tabular}{clcll}
\hline No & Name & Code & Sector & Overall Score \\
\hline 1 & MK Land Holdings & 8893 & Property & 0.968 \\
2 & KUB Malaysia Berhad & 6874 & Service & 0.556 \\
3 & Muhibbah Engineering & 5703 & Construction & 0.487 \\
4 & WTK Holdings & 4243 & Industry & 0.378 \\
5 & Unisem & 5005 & Technology & 0.135 \\
\hline
\end{tabular}

\section{Conclusions}

This paper applies MST as a filtering tool to construct a financial network of 125 Malaysian shariah-compliant stocks which are consistently listed in SAC's list. The data collected is divided into three periods namely pre-crisis (2000-2006), crisis (2007-2009) and post-crisis (2010-2017). This study aims to determine the topological structure of the Malaysian shariah-compliant stocks and identify the most influential stocks in each duration by using four centrality measures which are degree centrality, betweenness centrality, closeness centrality and eigenvector. The overall characteristic of each stock was presented by computing an overall centrality measure using PCA.

Generally, there were seven main clusters during pre-crisis period and three main clusters during crisis period. KUB Malaysia Berhad (6874) was the most important stock during both periods. Next, post-crisis network portrays five main clusters with MK Land Holdings (8893) was the most influential stocks among the five stocks. The service sector was a prominent sector during pre-crisis and during crisis periods, while during the post-crisis period, property sector was the strongest sector.

In terms of overall centrality measures which concluded all the four centrality measures, KUB Malaysia Berhad (6874) played a very crucial role in the networks during pre-crisis and crisis periods. It has the highest scores in all centrality measures in both pre-crisis and post-crisis periods. However, in the post-crisis period, MK Land Holdings (8893) replaced KUB Malaysia Berhad (6874) as the highest scoring stock in the overall centrality measure. Not only that, Unisem (5005) also contributed as an important stock although it does not have the highest score, but it appears in all three periods. Hence, service sector was an important sector before and during the financial crisis, whereas property sector was an important sector after financial crisis. Lastly, technology sector was considered as crucial sector since it emerges in the top five list of overall centrality measure across the periods of study. Above all, these findings may benefit investors who are interested in shariah-compliant stocks and consequently to determine which sectors and stocks they should invest in.

\section{Acknowledgement}

This research was supported by Ministry of Higher Education (FRGS 15-191-0432) and International Islamic University Malaysia (P-RIGS18-031-0031).

\section{References}

Asrah, N. M., Djauhari, M. A., \& Mohamad, I. (2017). PLUS highway network analysis: Case of in-coming traffic burden in 2013. AIP Conference Proceedings, 1842(October 2017). https://doi.org/10.1063/1.4982846

Bahaludin, H., Abdullah, M. H., \& Salleh, S. M. (2015). Minimal Spanning Tree for 100 Companies in Bursa Malaysia. In The 2nd ISM International Statistical Conference 2014. (Vol. 1643, pp. 609-615). https://doi.org/10.1063/1.4907501

Bonacich, P. (1987). Power and Centrality : A Family of Measures. American Journal of Sociology, 92(5), 11701182. http://dx.doi.org/10.1086/228631

Bonanno, G., Caldarelli, G., Lillo, F., Miccichè, S., Vandewalle, N., \& Mantegna, R. N. (2004). Networks of Equities in Financial Markets. European Physical Journal B, 38(2), 363-371. https://doi.org/10.1140/epjb/e2004-00129-6

Cheong, S., Fornia, R., Gladys, L., Kok, J., Yim, W., Xu, D., \& Zhang, Y. (2012). The Japanese Economy in Crises : A Time Series Segmentation Study. The Open-Access, Open-Assessment E-Journal, 6(5). https://doi.org/http://dx.doi.org/10.5018/economics- ejournal.ja.2012-5

Coletti, P. (2016). Comparing minimum spanning trees of the Italian stock market using returns and volumes. Physica A: Statistical Mechanics and Its Applications, 463, 246-261. https://doi.org/10.1016/j.physa.2016.07.029 
Coletti, P., \& Murgia, M. (2016). The network of the Italian stock market during the 2008-2011 financial crises. Algorithmic Finance, 5(3-4), 111-137. https://doi.org/10.3233/AF-160177

Djauhari, M. (2012). A robust filter in stock networks analysis. Physica A: Statistical Mechanics and Its Applications, 391(20), 5049-5057. https://doi.org/10.1016/j.physa.2012.05.060

Djauhari, M. A., \& Gan, S. L. (2013). Minimal spanning tree problem in stock networks analysis: An efficient algorithm. Physica A: Statistical Mechanics and Its Applications, 392(9), 2226-2234. https://doi.org/10.1016/j.physa.2012.12.032

Djauhari, M. A., \& Gan, S. L. (2014). Bursa Malaysia stocks market analysis: A review. ASM Science Journal, $8(2), 150-158$.

Djauhari, M. A., \& Gan, S. L. (2014). Optimality problem of network topology in stocks market analysis. Physica A: Statistical Mechanics and Its Applications, 419(2015), 108-114. https://doi.org/10.1016/j.physa.2014.09.060

Djauhari, M. A., \& Gan, S. L. (2015). Optimality Problem of Network Topology in Stocks Market Analysis. Physica A: Statistical Mechanics and Its Applications, 419, 108-114. https://doi.org/10.1016/j.physa.2014.09.060

Freeman, L. C. (1977). A Set of Measures of Centrality Based on Betweenness. Sociometry, 40(1), 35-41. https://doi.org/10.2307/3033543

Freeman, L. C. (1978). Centrality in Social Networks Conceptual Clarification. Social Networks, 1(1968), 215239. https://dx.doi.org/10.1016/0378-8733(78)90021-7

Graham, R. L., \& Hell, P. (1985). On the History of the Minimum Spanning Tree Problem. Annals of the History of Computing, 7(1), 43-57. https://doi.org/10.1109/MAHC.1985.10011

Jang, W., Lee, J., \& Chang, W. (2011). Currency crises and the evolution of foreign exchange market: Evidence from minimum spanning tree. Physica A: Statistical Mechanics and Its Applications, 390(4), 707-718. https://doi.org/10.1016/j.physa.2010.10.028

Jolliffe, I. T. (2002). Principal Component Analysis. Springer Series in Statistics (Second Edi, Vol. 98). Springer. https://doi.org/10.1007/b98835

Keskin, M., Deviren, B., \& Kocakaplan, Y. (2011). Topology of the correlation networks among major currencies using hierarchical structure methods. Physica A: Statistical Mechanics and Its Applications, 390(4), 719730. https://doi.org/10.1016/j.physa.2010.10.041

Laud, P. (2015). Parallel Oblivious Array Access for Secure Multiparty Computation and Privacy-Preserving Minimum Spanning Trees. Proceedings on Privacy Enhancing Technologies, 2015(2), 188-205. https://doi.org/10.1515/popets-2015-0011

Lee, G., \& Djauhari, M. (2012). Stock Networks Analysis in Kuala Lumpur Stock Exchange. Malaysian Journal of Fundamental and Applied Sciences, 8(2). https://doi.org/10.11113/mjfas.v8n2.124

Lee, G. S., \& Djauhari, M. A. (2012). An Overall Centrality Measure: The Case of US Stock Market. International Journal of Basic \& Applied Science, 12(06), 99-104.

Majapa, M., \& Gossel, S. J. (2016). Topology of the South African stock market network across the 2008 financial crisis. Physica A, 445, 35-47. https://doi.org/10.1016/j.physa.2015.10.108

Malkevitch, J. (2012). Trees: A Mathematical Tool for All Seasons. American Mathematical Society, Feature Column, 1-16.

Mantegna, R. (1999). Hierarchical Structure in Financial Markets. Eur. Phys. J. B, 11, 193-197. http://dx.doi.org/10.1007/s100510050929

Mantegna, R. N., \& Stanley, H. E. (2000). An Introduction to Econophysics: Correlations and Complexity in Finance (Vol. 1). https://dx.doi.org/10.1063/1.1341926

Nesetril, J. (1997). A Few Remarks on the History of MST Problem. Archivum Mathematicum, 33(1-2), 15-22.

Pasini, G. (2017). Principal Component Analysis for Stock Portfolio Management. International Journal of Pure and Apllied Mathematics, 115(1), 153-167. https://doi.org/10.12732/ijpam.v115i1.12

Securities Commission Malaysia. (2018). List of Shariah-Compliant Securities by the Shariah Advisory Council of the Securities Commission Malaysia. 
Sharif, S., \& Djauhari, M. A. (2012a). A proposed centrality measure: The case of stocks traded at Bursa Malaysia. Modern Applied Science, 6(10), 62-69. https://doi.org/10.5539/mas.v6n10p62

Sharif, S., \& Djauhari, M. A. (2012b). Worker's behaviour in manufacturing industry: An evidence from a minimum spanning tree. Malaysian Journal of Fundamental \& Applied Sciences, 8(1), 44-48. https://doi.org/http://dx.doi.org/10.11113/mjfas.v8n1.373

Yee, L., \& Salleh, R. (2018). Bursa Malaysia performance: Evidence from the minimum spanning tree. AIP Conference Proceedings, 1974(040015). https://doi.org/10.1063/1.5041689

Yee, L., Salleh, R., \& Asrah, N. (2018). Multidimensional Minimal Spanning Tree : The Bursa Malaysia. Journal of Science and Technology, 10(2), 136-143. https://doi.org/https://10.30880/jst.2018.10.02.022

Zhuang, R., Hu, B., \& Ye, Z. (2008). Minimal spanning tree for Shanghai-Shenzhen 300 stock Index. In 2008 IEEE Congress on Evolutionary Computation, CEC 2008 (pp. 1417-1424). https://doi.org/10.1109/CEC.2008.4630980.

\section{Appendix}

Table 16. The list of stocks from the year 2000 to the year 2017

\begin{tabular}{|c|c|c|c|c|c|}
\hline No & Name & Code & No & Name & Code \\
\hline 1 & Ajinomoto & 2658 & 13 & Emico Holdings & 9091 \\
\hline 2 & Amtek Holdings & 7051 & 14 & Federal International Holdings & 8605 \\
\hline 3 & Cck Consolidated Hdg. & 7035 & 15 & Hwa Tai Industries & 8478 \\
\hline 4 & Cwg Holdings & 9423 & 16 & Khee San & 6203 \\
\hline 5 & Khind Holdings & 7062 & 17 & Computer Forms (Mal.) & 8044 \\
\hline 6 & Kuantan Flour Mills & 8303 & 18 & Concrete Engr.Prds. & 8435 \\
\hline 7 & Lay Hong & 9385 & 19 & Ata Ims & 8176 \\
\hline 8 & Ltkm & 7085 & 20 & Fima Corporation & 3107 \\
\hline 9 & Mintye & 5886 & 21 & Golden Pharos & 5649 \\
\hline 10 & Nestle (Malaysia) & 4707 & 22 & Kia Lim & 6211 \\
\hline 11 & Paragon Union & 9407 & 23 & Kim Hin Industry & 5371 \\
\hline 12 & Pccs Group & 6068 & 24 & Kumpulan H\&L High-Tech & 7033 \\
\hline 25 & Rex Industry & 9946 & 68 & Kym Holdings & 8362 \\
\hline 26 & Sand Nisko Capital & 7943 & 69 & Lb Aluminium & 9326 \\
\hline 27 & Shh Resources Holdings & 7412 & 70 & Master-Pack Group & 7029 \\
\hline 28 & Sinotop Holdings & 8532 & 71 & Mce Holdings & 7004 \\
\hline 29 & Teo Guan Lee Corporation & 9369 & 72 & Mentiga Corporation & 5223 \\
\hline 30 & Umw Holdings & 4588 & 73 & Mieco Chipboard & 5001 \\
\hline 31 & Yee Lee Corporation & 5584 & 74 & Minho (M) & 5576 \\
\hline 32 & Alcom Group & 2674 & 75 & Perstima.Mal.(Perstima) & 5436 \\
\hline 33 & Amalgamated Indl.Steel & 2682 & 76 & Poly Glass Fibre (M) & 8117 \\
\hline 34 & Anzo Holdings & 9342 & 77 & Public Packages Hdg. & 8273 \\
\hline 35 & Apm Automotive Hdg. & 5015 & 78 & Quality Concrete Hdg. & 7544 \\
\hline 36 & Atta Global Group & 7099 & 79 & Sarawak Cons.Inds. & 9237 \\
\hline 37 & Boustead Heavy Industries & 8133 & 80 & Scientex & 4731 \\
\hline 38 & Central Industrial Corporation & 8052 & 81 & Seacera Group & 7073 \\
\hline 39 & Chin Well Holdings & 5007 & 82 & Turiya & 4359 \\
\hline 40 & Choo Bee Metal Inds. & 5797 & 83 & Southern Acids (M) & 5134 \\
\hline 41 & Cme Group & 7018 & 84 & Subur Tiasa Holdings & 6904 \\
\hline 42 & Ta Ann Holdings & 5012 & 85 & Ipmuda & 5673 \\
\hline 43 & Teck Guan Perdana & 7439 & 86 & Konsortium Transnasional & 4847 \\
\hline 44 & Timberwell & 7854 & 87 & Kpj Healthcare & 5878 \\
\hline 45 & Tong Herr Resources & 5010 & 88 & Kub Malaysia Berhad & 6874 \\
\hline 46 & Vs Industry & 6963 & 89 & Mega First Corporation & 3069 \\
\hline 47 & White Horse & 5009 & 90 & Mesb & 7243 \\
\hline 48 & Wong Engineering Corporation & 7050 & 91 & Ocb & 5533 \\
\hline 49 & Woodlandor Holdings & 7025 & 92 & Pdz Holdings & 6254 \\
\hline
\end{tabular}




\begin{tabular}{llllll}
50 & Wtk Holdings & 4243 & 93 & Permaju Industries & 7080 \\
51 & Mtd Acpi Engineering & 5924 & 94 & Petronas Dagangan & 5681 \\
52 & Fajarbaru Builder Group & 7047 & 95 & See Hup Consolidated & 7053 \\
53 & Ho Hup Construction & 5169 & 96 & Sime Darby & 4197 \\
54 & Hock Seng Lee & 6238 & 97 & Telekom Malaysia & 4863 \\
55 & Ijm Corporation & 3336 & 98 & Tenaga Nasional & 5347 \\
56 & Kumpulan Jetson & 9083 & 99 & Ums Holdings & 7137 \\
57 & Mercury Industries & 8192 & 100 & Utusan Melayu (Malaysia) & 5754 \\
58 & Merge Energy & 5006 & 101 & Yinson Holdings & 7239 \\
59 & Mitrajaya Holdings & 9571 & 102 & Genting Plantations & 2291 \\
60 & Muhibbah Engineering (M) & 5703 & 103 & Batu Kawan & 1899 \\
61 & Sycal Ventures & 9717 & 104 & Far East Holdings \\
62 & Vizione Holdings & 5029 & 105 & Jaya Tiasa Holdings & 5029 \\
63 & Wct Holdings & 9679 & 106 & Kuala Lumpur Kepong & 4383 \\
64 & Zecon & 7028 & 107 & Kwantas Corporation & 2445 \\
65 & Brahim's Holdings & 9474 & 108 & Pls Plantations & 6572 \\
66 & Fiamma Holdings & 6939 & 109 & Sarawak Oil Palms \\
67 & Sin Heng Chan (Malaya) & 5126 & 110 & Mk Land Holdings & 9695 \\
111 & Innoprise Plantations & 4316 & 119 & Oriental Interest & 5126 \\
112 & United Plantations & 6262 & 120 & Tiger Synergy & 8893 \\
113 & Ideal United Bintang International & 2089 & 121 & Malaysian Pacific Inds. & 5827 \\
114 & Amverton & 9687 & 122 & Mesiniaga & 7079 \\
115 & Ark Resources Holdings & 5959 & 123 & Unisem (M) & 3867 \\
116 & Bina Darulaman & 7007 & 124 & Bimb Holdings & 5011 \\
117 & Crescendo Corporation & 6173 & 125 & Syarikat Takaful Malaysia & 5005 \\
118 & Grand Hoover & 7010 & & & 5258 \\
\hline & & & & & 6139 \\
\hline
\end{tabular}

\section{Copyrights}

Copyright for this article is retained by the author(s), with first publication rights granted to the journal.

This is an open-access article distributed under the terms and conditions of the Creative Commons Attribution license (http://creativecommons.org/licenses/by/4.0/). 